\title{
A carpintaria naval do nordeste paraense
}

\section{The naval carpentry of northeastern Pará.}

Carlos Eduardo Rangel Andrade* \& Manuel Fernando Santos

Instituto de Estudos Costeiros, Universidade Federal do Pará - UFPA

*E-mail: eduardora@ufpa.br

Recebido: 1 de junho de 2017 / Aceito: 11 de agosto de 2017 / Publicado: 6 de dezembro de 2017

Resumo As pescarias artesanais do nordeste paraense são realizadas principalmente com embarcações de madeira. Em face da diversidade de recursos, a frota pesqueira também apresenta uma enorme diferença na apresentação das embarcações construídas nessa região. Caracteriza-las é uma tarefa das mais difíceis, levando-se em conta as mudanças providas em face da parca base teórica do proprietário, não obstante o estilo regional continuar resistindo às modificações. Para o registro deste trabalho foi elaborado um memorial descritivo, apresentando os aspectos e as técnicas empregadas na construção artesanal naval das embarcações na cidade de Bragança, nordeste paraense, distinguindo as peculiaridades regionais e o típico arranjo arquitetônico dessas embarcações concebidas nesse local, suas partes componentes, bem como o registro do modo tradicional de construção, as técnicas habituais e as alterações aplicadas em face das exigências do proprietário.

Palavras-chave: Embarcação de madeira, Construção artesanal, Estilo de construção naval.

\begin{abstract}
The artisanal fisheries of the northeast of Pará State are mainly made with wooden boats. Given this diversity of fishing resources, the fishing fleet also features an enormous difference in the presentation of the boats built in this region. Characterize them is the most challenging task, considering the changes provided in the face of the owner's whim, regardless of the regional style continues resisting the changes. For the record of this work was done a descriptive memorial, presenting the aspects and techniques used in naval craft construction of boats in the city of Bragança Pará, distinguishing the regional peculiarities and the typical architectural arrangement of these boats designed in this site, its component parts, as well as the registration of the traditional way of construction, the usual techniques often employed, and changes implemented in the face of the owner's requirements.
\end{abstract}

Keywords: wood craft, craft construction, shipbuilding style. 


\section{Introdução}

Reconhecer os saberes da tradição é mais que um artifício acadêmico ou um argumento de retórica, pois trata de afirmá-los como conhecimento pertinente que está inserido em um contexto (Morin, 1991), para os quais, segundo Almeida em Moraes (2007), compreender sua anterioridade requer reconhecer a importância inestimável dos mesmos para a consolidação da cultura contemporânea e, em particular, para a construção da ciência.

Nesse contexto, a construção naval artesanal não foge à regra, quer em relação às técnicas de captura empregadas, quer em relação ao tipo de embarcações comumente utilizadas. Apesar de toda a tecnologia disponível nos dias atuais, muito dos métodos empregados na pesca artesanal ainda remontam há séculos atrás, principalmente no tocante às embarcações.

Os saberes não científicos ligados a populações tradicionais envolvem relações estreitas entre o homem e a natureza, permeados por relações de ordens pontuais e também míticas. São conhecimentos transmitidos das gerações mais experientes para as mais jovens, principalmente pela oralidade e pelas práticas do cotidiano (Moraes 2007).

Inegável afirmar que os primeiros construtores navais da Amazônia foram os índios. Nos primórdios, a canoa era o principal meio de transporte dos indígenas amazônicos. Os troncos de paus que caiam nos rios, boiando conforme a correnteza, foram a inspiração das primeiras embarcações elaboradas por eles. O casco era feito da casca do tronco moldada com amarração de cipó, podendo ser construído ainda, com um único tronco de arvore cavado a fogo ou a machado. A correnteza, o remo e a força eram os recursos utilizados pelos índios, que além de possuírem grande habilidade da navegação fluvial, conheciam bem as águas singradas (Bittencourt,1957). Na atualidade, ainda se pode ver a capacidade inata do ribeirinho, no que tange a construção naval. “... todos os nativos são bons construtores de embarcações. Ouvi muitas vezes da boca de brancos, que um índio é carpinteiro e armador por intuição". Declaração que valida a cultura naval do caboclo (Moacir Andrade, 1957).

Os cascos utilizados nas regiões dos campos naturais de Bragança e Tracuateua e em algumas localidades ao longo do Rio Caeté, ainda são confeccionados com técnicas quase iguais as utilizadas pelas populações indígenas do tempo do descobrimento e os nossos barcos artesanais ainda são heranças da carpintaria naval praticada no período colonial.

No entanto, na região campeira bragantina, essa tendência de construir cascos extraídos dos troncos de madeira tende a ser cada vez mais rara em virtude de fatores como: a dificuldade de encontrar árvores que sirvam para a extração dessas canoas, a perda das técnicas usadas pelos antigos mestres carpinteiros que não foram repassadas as novas gerações e a interligação entre as ilhas por ramais que cruzam as áreas alagadas, facilitando o deslocamento durante o inverno, abolindo o uso dessas embarcações que eram antes, usadas para esses fins. Atualmente, a utilização dos antigos cascos é feita somente em algumas formas de pescarias que ainda são praticadas nos campos alagados durante a estação chuvosa.

Já nas áreas estuarinas da região bragantina, frequentemente sujeitas ao regime de marés, a diversidade de estilos de embarcações usadas no deslocamento de pessoas e na pesca, foi marcante antes do advento das ligações terrestres entre as localidades da região.

\section{Peculiaridades da construção naval do nordeste paraense}

Nas pescarias de águas interiores existem unicamente embarcações artesanais, todas de madeira, divididas em canoas e barcos geleiros. As canoas (mais primitivas) não possuem nenhum tipo de cobertura e frequentemente não utilizam qualquer método para a conservação do pescado (IBAMA, 1997). Já as embarcações motorizadas podem alcançar $10 \mathrm{~m}$ de comprimento e transportar em média $500 \mathrm{~kg}$ de pescado (SEAP/IBAMA - Diagnóstico da Pesca e da Aquicultura no Estado do Pará - Pesca Artesanal, Belém-Pará, 2008).

Nesse contexto, a interação e o desenvolvimento sócio econômico dessa região, onde a grande maioria das cidades ou vilas localiza-se à beira dos rios, são compostos fortemente pela pesca, a qual insere naturalmente à prática da carpintaria naval. Segundo Silva et al (2007), observa-se que considerável número de embarcações (paraenses) são de madeira e produzidas na própria região por mestres carpinteiro navais. Embora sejam produzidas em estaleiros a partir de procedimentos empíricos.

No nordeste paraense, onde a pesca estuarina é muito forte em face de sua posição geográfica, a grande diversidade de embarcações também é proporcional à heterogeneidade da pesca aqui praticada. Isto, porém, não faz dessas embarcações uma especificidade pesqueira, muitas acabam sendo adaptadas e direcionadas 
conforme a necessidade de seu dono. Por força dessas variáveis são produzidas embarcações dos mais diversos tipos, desde simples canoas até barcos de grande porte.

Com toda essa diversidade, classificar adequadamente esse universo naval de embarcações artesanais de madeira tem sido objeto de discussão, até mesmo quando são realizadas por entidades oficiais do governo.

Segundo Salorte (2010), pouca coisa se conhecia da estabilidade, efeitos das ondas e vento, resistência ao avanço e outros conceitos modernos como o da resistência de materiais. A construção naval era forjada pela padronização nos chamados "traçados" que consistiam numa compilação de proporções, dimensões e regras que permitiam desenhar e dimensionar vários tipos de embarcações e se destinavam diretamente aos carpinteiros navais, sem grandes conhecimentos teóricos para construir navios. Essa padronização estava descrita no Livro das Traças de Manuel Fernandes, editado em Lisboa em 1616. Desde então, a construção naval começou a passar por profundas transformações, pois até quase o final do século XVIII o projeto dos navios era quase inteiramente empírico, tendo como único embasamento científico a lei do empuxo (princípio de Arquimedes).

Particularmente, na Amazônia, a indústria naval tradicional é aquela que tem como produto principal as embarcações regionais (que pescam), transportam cargas e passageiros e são construídas com matérias primas oriundas da Floresta Amazônica (Lins, 2006), com cenário totalmente diferente daquele descrito anteriormente para o Brasil e o mundo. As necessidades são outras, as realidades são diferentes. Porém, enquanto continentes se ajustam para serem mais competitivos, a construção naval local é principiante na utilização de novas tecnologias e recursos para fabricação de pequenas embarcações para atender as necessidades regionais (Tonete, 2008).

Esse trabalho tem o objetivo de relatar a construção artesanal de embarcações de madeira no nordeste paraense. Em suma, fazer um estudo e registro dessas peculiaridades para identificar e inventariar as técnicas de construção naval, possibilitando manter um resguardo destas, para que as próximas gerações possam combater a falta de interesse de aprendizado dessa arte artesanal característica de nossa construção naval.

\section{Material e Métodos}

Para a realização desse trabalho foram feitas visitas aos dois principais estaleiros de Bragança do Pará localizados às margens do Rio Caeté, próximos a Ponte do Sapucaia, com o objetivo de descrever a dinâmica de atuação da construção naval do nordeste paraense. O estudo foi realizado durante seis meses, tendo em média duas visitas mensais, no período compreendido entre de julho de 2011 a dezembro do mesmo ano. Em tais visitas, além de registros fotográficos, foram anotados com o uso de questionários semiestruturados, peculiaridades acerca da construção naval do nordeste paraense. Essa transcrição teve como finalidade apresentar as medidas usuais empregadas, tanto das dimensionalidades gerais, como as de cada compartimento, além das bitolas utilizadas nas peças estruturais.

Serviu também para o delineamento das divisões internas e dos demais elementos que compõem o arranjo estrutural e arquitetônico de uma embarcação artesanal.

\section{Resultados}

\section{Processo de construção}

\section{ENCOMENDA DO BARCO}

Via de regra, a encomenda de uma embarcação artesanal de madeira é feita diretamente pelos proprietários, que são pescadores ou patrões de pesca com larga experiência nessa atividade. A definição do tipo e/ou tamanho que será encomendado é, muitas vezes, relacionada à potência do motor que já dispõem ou pretendem comprar. "O motor é que influencia o barco: largo ou estreito, maior ou menor, tudo a gosto do freguês. Ele (o armador) é quem define como quer", Mestre Louro.

Dentro deste contexto, a grande maioria não faz uma definição antecipada do tipo de pescaria que será praticada, para que seja possível determinar padrões para a embarcação que será encomendada, mas sim, em decorrência da simples oportunidade da aquisição de um novo barco.

Como a possibilidade de adequação pesqueira é muito ampla, apenas o tamanho do barco é a linha limitante de atuação, direcionando-o para a pescaria em que for possível enquadra-lo, somando-se a isso às diversas safras de pesca ocorridas durante o ano. 


\section{QUAL O MELHOR DESENHO DE BARCO?}

A resposta naturalmente não é simples. O máximo que se pode fazer é identificar um casco que atenda as expectativas do armador relacionado ao tipo de uso (diversidade de pesca ou tipo de transporte).

\section{PAGAMENTO DA ESTADIA POR OCUPAR UM LUGAR NO ESTALEIRO DURANTE A CONSTRUÇÃO.}

Esse valor não segue uma regra fixa e varia de acordo com cada situação. Para os barcos grandes, o valor gasto em meados de 2011 no Estaleiro Sapucaia, era de R \$150,00 por semana, porém se a construção fosse interrompida, cessaria esse pagamento. Os barcos de tamanho médio, em torno de $\mathrm{R} \$ 100,00$ e, para os menores, não existe um valor fixo definido. "Varia de acordo com o que a semana dá. Até mesmo para os médios, esse valor já não é certo, tudo depende do ritmo do trabalho", Mestre Louro.

Durante o período da confecção da embarcação e conforme a necessidade, o restante do pagamento é feito aos poucos. Desses valores recebidos ainda são feitos os pagamentos de energia e da estadia do barco no estaleiro.

\section{A MADEIRA UTILIZADA PARA A CONSTRUÇÃO DE EMBARCAÇÕES ARTESANAIS}

A madeira utilizada é a de lei (o cumaru (Dipteryx odorata), o piquiá (Caryocar villosum), sapucaia (Lecythis pisonis), o ipê ou pau d'árco (Tabebuia spp), a tatajuba (Bagassa guianensis) e o louro vermelho (Nectandra rubra), ou seja, madeiras duras, próprias para construções, que possuem qualidades fisiológicas que permitem resistir às oscilações de temperatura e ataques biológicos. Decerto que diante da atual conjuntura, essa diversidade de espécies utilizadas tende a aumentar.

O conhecimento empírico dos construtores navais é suficiente para definir quais os tipos de madeiras serão adequados para cada setor específico da embarcação, para tal eles levam em consideração fatores como resistência, resiliência, durabilidade, etc. Intuitivamente, um tipo de madeira é aprovado ou não e, nesse caso, pode limitar-se o uso à apenas uma espécie - como é o caso do piquiá usado para a confecção das cavernas ou ter-se opções de escolha.

Nos presentes dias, a pouca disponibilidade de madeira é um fator considerável que leva à grande variação de tempo para a construção de uma embarcação. Conseguir peças que sejam adequadas à construção naval é uma tarefa muito difícil, dada a intensificação de fiscalização dos órgãos ambientais e ao fato do mercado madeireiro ser mais voltado à construção civil e, por conseguinte, a madeira disponível ser beneficiada, em maior quantidade, em formatos que atendam a essa exigência de mercado.

\section{QUILHA}

A quilha do barco é uma peça estrutural posicionada longitudinalmente, construída por uma única tora de madeira, de seção moderadamente retangular, sobre a qual são fixadas as cavernas, que são as (peças da estrutura primária de uma embarcação).

A escolha da espécie de madeira que será usada, bem como a retilineidade e a qualidade de lenho desse artefato, são três dos requisitos mais importantes para a estrutura de uma embarcação e exige enorme responsabilidade de seleção. "A madeira da quilha do barco tem que ser forte e dura, que possa aguentar o arrastado do fundo do barco na areia, o encontro com troncos debaixo d'água e suportar também o peso do barco quando ele estiver em seco. Por isso se usa cumaru, sapucaia, tatajuba ou outra madeira que seja resistente na água". Mestre Louro (figura 1).

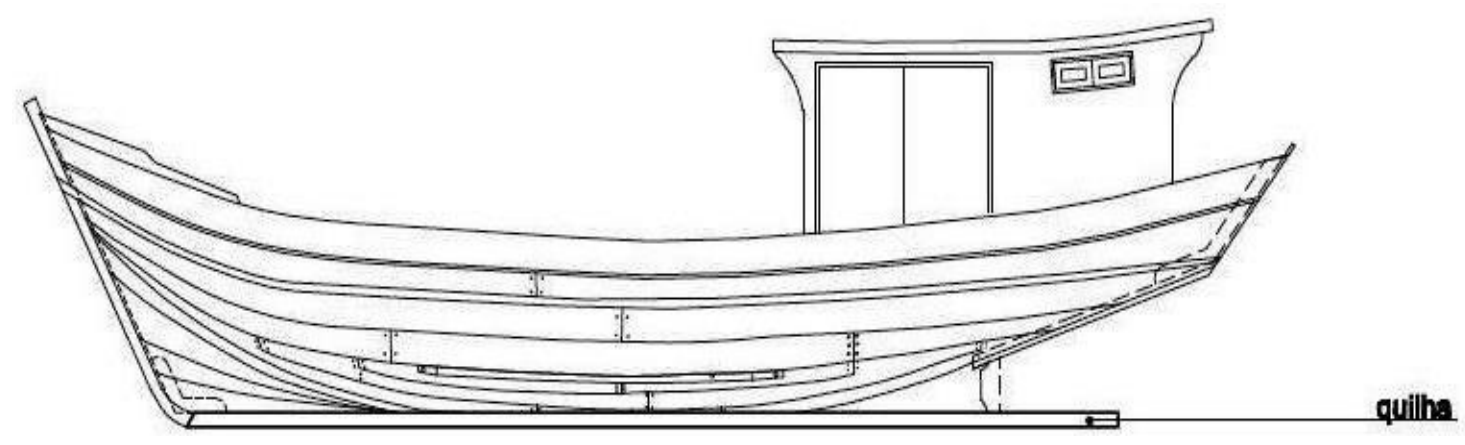

Figura 1. Desenho esquemático de um barco representado a quilha. 
Acta of Fisheries and Aquatic Resources

O dimensionamento da quilha em relação ao tamanho da embarcação, segundo os construtores artesanais, é de aproximadamente $75 \%$ do comprimento total. Porém, isto não é uma regra e esse percentual sofre muitas variações em face dos cálculos que determinam a composição dessa peça, serem totalmente empíricos, determinados apenas pelo mestre naval.

\section{DEMAIS PEÇAS ESTRUTURAIS DE UMA EMBARCAÇÃO E SUAS CARACTERÍSTICAS}

Notadamente, as principais peças estruturais de uma embarcação são fixadas sobre a quilha ou em sequência das demais peças montadas sobre esta (Figura 2).

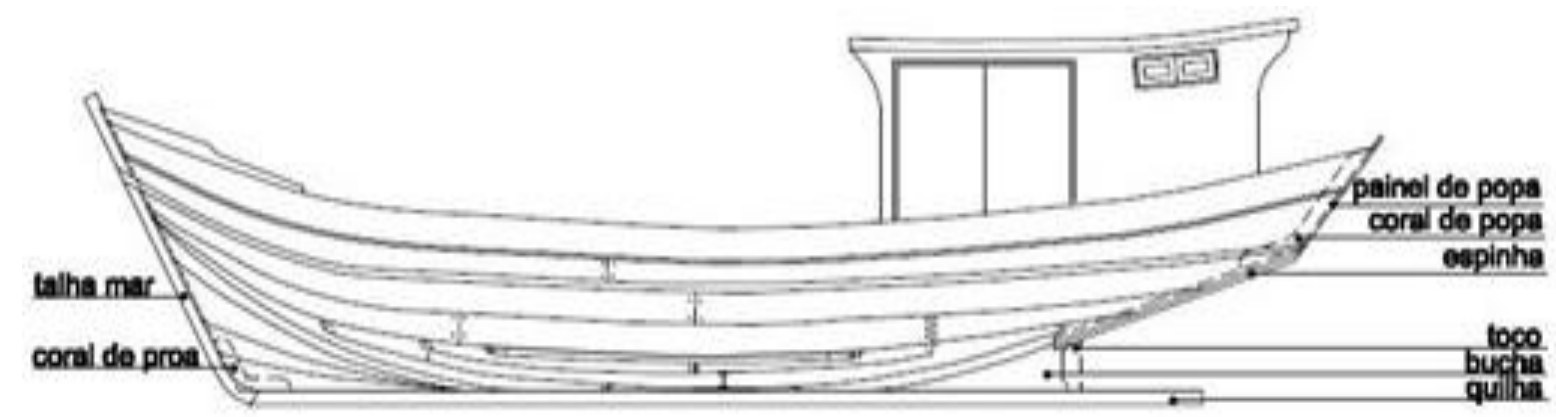

Figura 2. Apresentação esquemática das demais peças estruturais do barco.

\section{OS CORAIS}

Os corais são peças de conexão estrutural. O coral de proa, fixado na extremidade de vante da quilha, tem como desempenho estruturar a junção entre a quilha e o talha-mar (aresta frontal). Na parte antagônica, na popa, é montado o coral de popa, servindo de conexão estrutural para as peças que compõem a parte de ré da embarcação (Figura 3 a e b).

\section{O TALHA-MAR}

O talha mar é a aresta frontal da embarcação. É uma peça estrutural reta, montada de forma inclinada, como um prolongamento da quilha, servindo ainda para a amarração do tabuamento de costado. "O talha mar é a peça dianteira, é o para choque do barco" Mestre Louro. Como é a principal peça estrutural de vante da embarcação, é ela que recebe o primeiro impacto quando do deslocamento do barco sobre as águas, daí o nome. (Figura 3c).

\section{PAINEL DE POPA}

É a madeira de fechamento superior da popa de uma embarcação. Seu desenho, apesar de existir uma concepção pré-determinada, tem seu corte totalmente influenciado pela concepção arquitetônica regional e pelo ponto de vista do mestre carpinteiro naval (figura 3d).

\section{BUCHA}

A bucha é um artefato que serve para proporcionar a inclinação da popa, sendo utilizada quando o motor da embarcação é de centro. Lembrando um triângulo retângulo, essa peça apresenta um furo no centro, ligando uma extremidade à outra. A sua dimensão e o ângulo de corte são determinados pelo tamanho da quilha e pelo grau de inclinação de outra peça estrutural - a espinha - sobre a qual será montado o painel de popa, em seu extremo superior (Figura 4a).

\section{ESPINHA}

A espinha é uma peça estrutural inclinada montada sobre a bucha. É fixada sequencialmente à parte de ré da quilha e serve para receber o coral de popa. Quanto ao tamanho, não existem regras precisas que a definam, porém, deve ser coerente para - de forma estruturalmente viável - receber o coral de popa, donde é fixado o painel. Sua fixação se dá por dois pares de parafusos amarrando-a ao coral de popa na parte superior e à bucha na parte inferior, sobre a quilha (Figura 4b). 


\section{TOCO}

Dependendo do tamanho da embarcação - geralmente para barcos a partir de 10 metros - emprega-se ainda um toco, que é uma peça atrelada à quilha, posicionado em pé, ao final da bucha, servindo para aumentar a base estrutural desta, evitando que as vibrações provocadas pelo funcionamento do motor desestabilizem esta peça. Notadamente, assim como a bucha, o toco receberá também um furo de passagem para encaixe do eixo propulsor. Essa peça ainda serve para aumentar a sustentação da espinha (Figura 4c).

\section{CAVERNAS}

Caverna é cada uma das peças curvas que formam o arcabouço de uma embarcação. As quatro cavernas principais, as de meia nau (o meio, o centro, a boca da embarcação), são as primeiras a serem talhadas e moldadas tradicionalmente, de acordo com a concepção característica da região.

Assim, em face de uma estimativa adequada para o calado, toda embarcação advém de, pelo menos, dois cálculos iniciais. Para a definição do dimensionamento de meia nau, os cálculos são gerados em face do tamanho da embarcação. Assim, utilizando-se um percentual de referência em torno de $1 / 4$ do comprimento total, estipula-se essa largura da boca, mas via de regra, esse valor é sempre dilatado.

O segundo cálculo é a determinação do pontal (distância do convés a quilha), profundidade do porão), em torno de 1/3 da largura de boca (largura da embarcação), porém, é muito comum a amplitude do resultado.

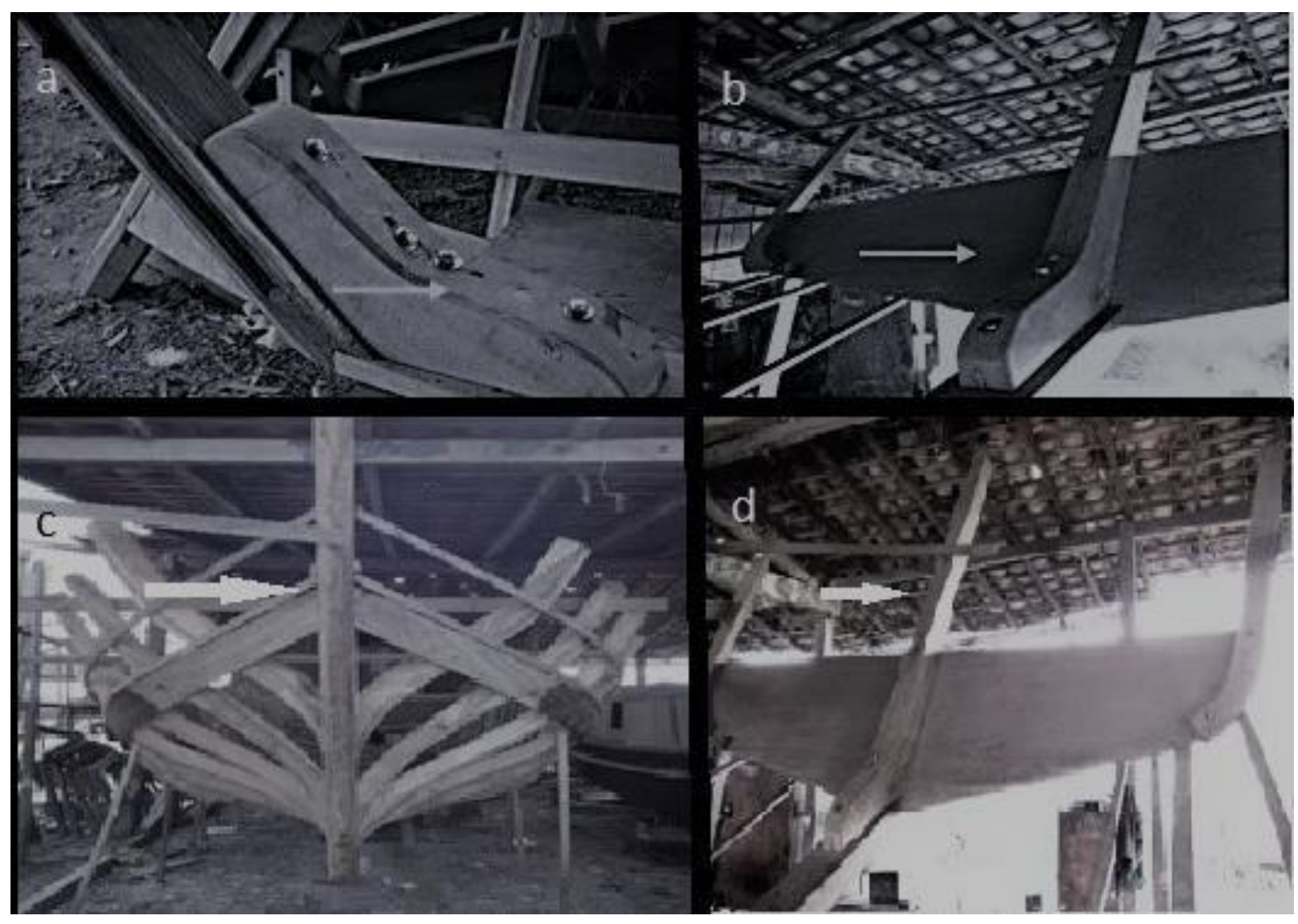

Figura 3. Principais peças estruturais que compõem uma embarcação confeccionada no nordeste paraense: a. coral de proa; b. coral de popa; c. Talha mar e d. painel de popa. 


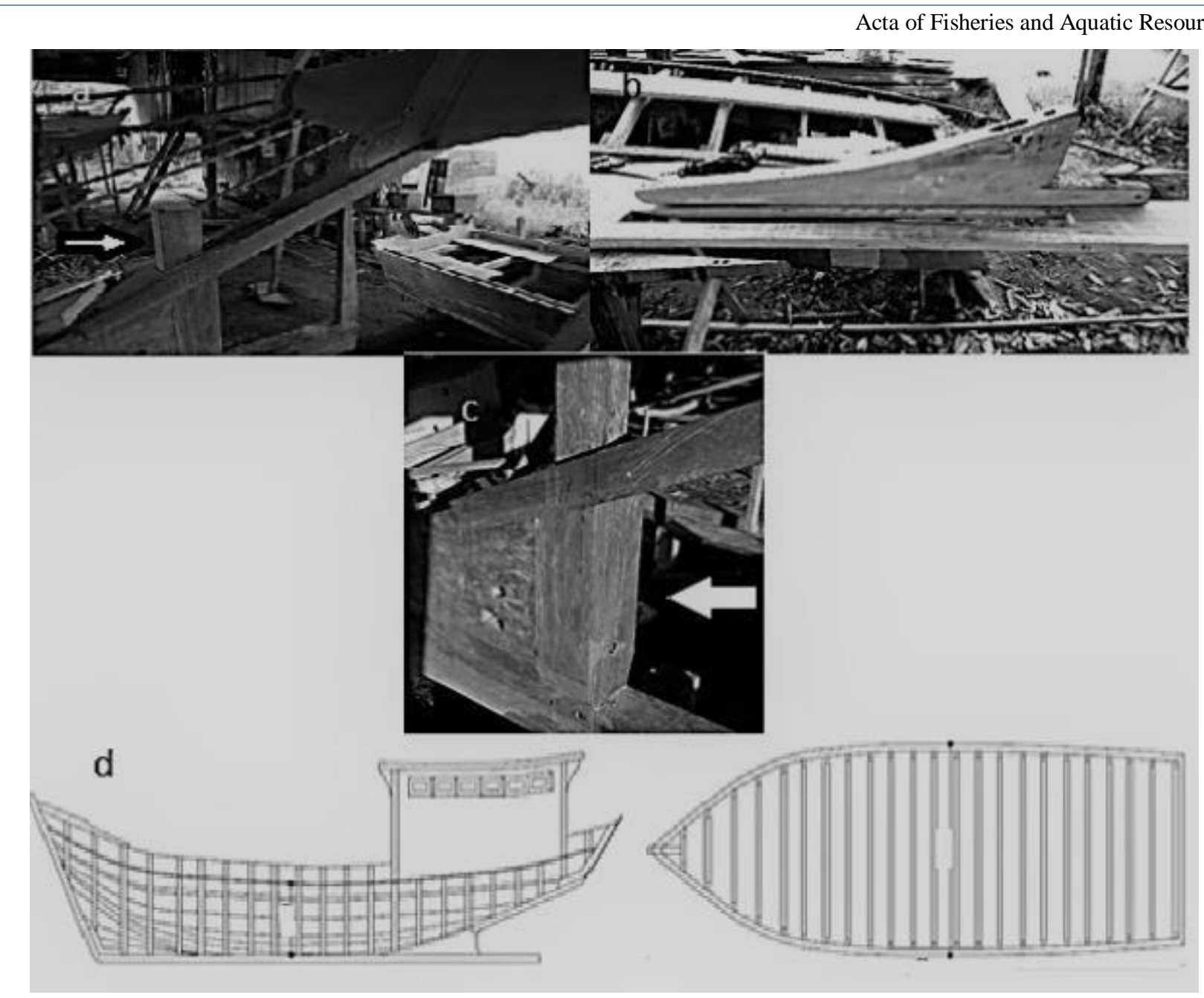

Figura 4. Demais peças estruturais que compõem uma embarcação confeccionada no nordeste paraense: a. bucha; b. espinha; c. toco e d. vista de perfil e superior do cavername com as suas cavernas.

\section{PREENCHIMENTO DO COSTADO}

As primeiras tábuas assentadas sobre a estrutura do cavername são as de talabardão. Servem para o cálculo do alvoro (linha lateral longitudinal, de bombordo e de boreste, levemente côncava, que propõe a curvatura típica do convés, o talho do barco) estipulado a gosto do mestre carpinteiro.

Utilizando uma técnica própria, é possível formar durante a pregaria do costado, uma lacuna entre as peças com a abertura maior voltada para o exterior do costado. Isto facilitará a calafetagem (vedação das juntas ou fendas do casco), em virtude desse procedimento ser feito de fora para dentro, na mesma sequência de pressão que a água exercerá sobre o casco do barco.

\section{CALAFETAGEM}

Calafetagem é a vedação dos interstícios existentes entre as peças de madeira que são usadas para a confecção de uma embarcação. Para essa vedação é utilizada fibra vegetal (muito comum o uso do algodão) tingida com zarcão em pó (tinta vermelha cuja base é óxido de chumbo) misturado com óleo comestível.

Ainda sobre essa calafetagem inicial é aplicada, com o auxílio de uma espátula, uma massa composta de óleo de mamona, (extraído da semente de mamona ou carrapateira (Ricinus communis L.), cal e cola líquida fixadora à base de epóxi que, além de reforçar a calafetagem primária ainda dará, depois de seca e lixada, um acabamento adequado para receber a pintura do casco.

A calafetagem só tornará a embarcação realmente estanque depois de seu lançamento à água, quando ocorrerá o encharque completo da madeira, proporcionando, através de sua dilatação e da expansão da fibra vegetal, a retração da espessura de cada brecha calafetada. 


\section{ALMA DO BARCO}

Um olhar mais preciso do casco já é suficiente para se identificar a região em que o barco foi construído. Quando a embarcação tem proa larga com o costado arredondado é de construção bragantina, quando o costado de proa é "fino" em forma de um "V" pode ser originado da região de Abaetetuba, município paraense. Já em alguns barcos cearenses, uma característica marcante é o aparecimento de um contorno de canto no casco, proveniente da concepção retilínea do corte das cavernas, produzindo uma quina no costado. Notadamente, apenas os barcos maiores é que detêm essas marcas tradicionais, excluindo os pequenos - de menor valor comercial - da "obrigatoriedade" dessa identificação. As canoas bragantinas, por exemplo, são construídas com contorno de canto (Figura 5).

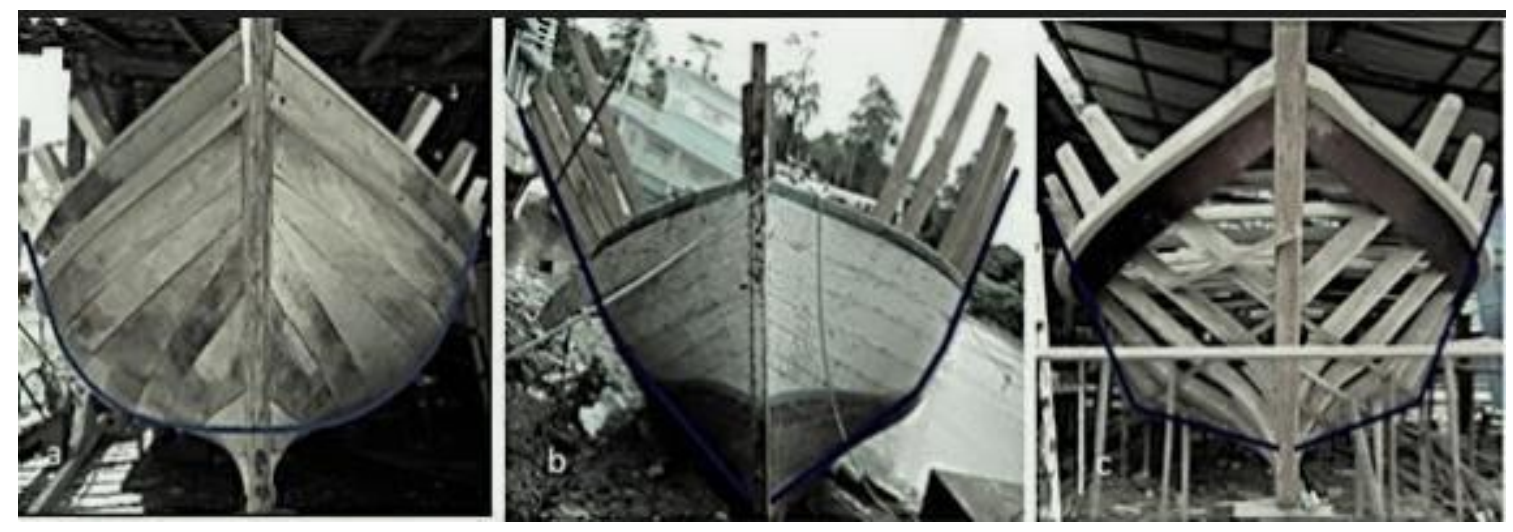

Figura 5. Diferentes formas como as cavernas são colocadas dependendo do local onde é feita a construção ("a"bragantina. "b" - abaetetubana e "c" - cearense).

\section{Discussão}

A tentativa de balancear a velocidade com economia de combustível, conforto ao navegar e ainda ter um custo baixo de construção, não é uma tarefa fácil de realizar (Marshall, 2002). Existem diferenças no que se refere ao formato de casco dos barcos dependendo da região onde foram construídos, diferenças estas que podem ser observadas no tipo de fundo, na relação boca/comprimento total, entre outras (Andrade 1983). Nos estaleiros de Bragança Do Pará, como existe uma conversão no que se refere a origem das embarcações, é possível se observar os diversos tipos de construção naval, indo desde os barcos com fundo em "V" até as embarcações com contorno de canto, como os construídos no Ceará.

Historicamente adaptando o meio às suas necessidades, o homem amazônico desenvolveu uma cultura de absorção de diversas espécies (de madeiras) na construção de suas embarcações. Vale ressaltar que, de acordo com a parte que se constrói da embarcação, diferentes espécies são utilizadas em razão das suas qualidades físicas e de manejo (Thecna, 2010). Cada madeira apresenta diferentes características fisiológicas no que se refere a dureza, resiliência, durabilidade, entre outros. (Burguer, L.M. \& Richter, H.G., 1991). O estudo acerca da carpintaria naval da frota artesanal do Maranhão, a escolha do material, assim como o dimensionamento das embarcações projetadas é feito por simples cálculos empíricos (Castro, 2008 e Moraes, 2007). Nas observações feitas no decorrer desse manuscrito, pode se notar que a mão de obra da carpintaria naval é advinda mais por herança do que por interesse de aprendizado das pessoas que estão fora desse círculo familiar. Esse saber técnico é repassado através das gerações quando o mais velho vai ensinando a arte aos mais novos. Notadamente, ainda existe a interferência do proprietário, dado a sua preferência por uma ou outra espécie, tudo em face de exemplos anteriores copiados de outras embarcações. Por isso o carpinteiro naval precisa ter um grande discernimento para aquilatar as melhores madeiras, as que podem ser usadas para o seu serviço de carpintaria, sua fragilidade e suporte, direcionando-as adequadamente para uso em um local específico da embarcação, apenas em função do conhecimento empírico das propriedades físicas e mecânicas dos diversos tipos existentes.

Decerto que, quanto mais rara fica a construção de barcos, mais difícil será manter viva a praticidade das técnicas construtivas e quiçá, seu ensinamento. Tem-se a impressão de que, nesse nosso universo pesqueiro, composto quase que totalmente por embarcações artesanais de madeira, os hábeis mestres construtores e os carpinteiros navais estão aí, inseridos, apenas como meros coadjuvantes, como se sua arte fosse mera casualidade no contexto pesqueiro. 
Acta of Fisheries and Aquatic Resources

Apesar de tão valiosos os seus ofícios, foi percebido durante o breve período de seis meses (tempo em que foram realizadas as entrevistas), que a existência desses competentes profissionais, é meramente ocasional, direcionado seu trabalho como apenas fruto do acaso. Assim, se faz necessário uma inventariada mais profunda de nosso universo artesanal naval, mais particularmente, o bragantino, tão característico e tradicional, para que assim seja possível melhor enumerá-lo, diagnosticá-lo e promover estratégias de sustentabilidade.

\section{Referências}

Andrade, M.; (1983) Tipos e Utilidades dos Veículos de Transportes Fluviais do Amazonas. Manaus. Ed. Impressa Oficial do Estado do Amazonas.

Bittencourt, A. (1957) Bacia Amazônica: Vias de Comunicação e Meios de Transporte. Rio de Janeiro. Ed. ACA, 1957.

Burguer, L.M. \& Richter, H.G. (1991) Anatomia da Madeira. São Paulo: Nobel.

Castro, L. (2008) Carpintaria Artesanal no Estado do Maranhão. Rev. Bras. Enga. Pesca, 3( 2): 163-169.

Ibama (1997) - Relatório da V reunião do grupo permanente de estudos GPE. Piramutaba. Belém: Ibama. (mimeo)

Ibama (2008) - Estatística da pesca 2005. Brasil. Grandes Regiões e Unidades da Federação. Ibama, 2007. In: Diagnóstico da Pesca no Pará, Artesanal-Belém.

Lins, N.V.M., Rodrigues, L. R. Q., Barreiros, N. R., Machado \& W. V. M. (2006). Construção Naval no Amazonas: Proposições para o Mercado, Projeto: Transporte Hidroviário e Construção Naval na Amazônia (THECNA), UFAM Amazonas.

Marshall, R. (2002). All Power Boat. New York: MacGraw Hill.

Moraes, S.C. (2007) Uma Arqueologia dos Saberes da Pesca - Amazônia e Nordeste. Belém: Editora Universitária UFPA.,

Morin, E. (1991) O Método IV - As Idéias: a sua natureza, vida, habitat e organização, Portugal.

Pereira, O.D. (1950). Direito Florestal Brasileiro. Rio de Janeiro: Borsoi, pg. 96.

Salorte, L.M.L. (2010) Carpinteiros dos Rios: o saber da construção naval no município de Novo Airão/AM. Dissertação (Mestrado em Sociedade e Cultura na Amazônia). Programa de Pós-Graduação, Universidade Federal do Amazonas, Manaus.

Silva, D.M.; Souza, J.O.; Vitelli, R.S.; Pereira, L.D.; Lima, J.B.; Moreira, A.L.S. (2007) Análise da metodologia utilizada no projeto e construção de embarcações de pequeno e médio portes na região metropolitana de Belém-PA. In: 59a Reunião da Sociedade Brasileira para o Progresso da Ciência-SBPC. Belém. Anais. Belém. CD-ROM.

Thecna (2010): Transporte Hidroviário e Construção Naval do Amazonas, Manaus - Amazonas, 2066 - 2009. Tonete, R.J. (2008). Embarcação de pequeno porte construída em madeira no Amazonas: Propostas e Itacoatiara.

Melhorias, Universidade Federal do Amazonas - Ufam, Instituto de Ciências e Tecnologia - Icet - 